\title{
Ultra-Fast Growth of ZnO Nanorods on Cotton Fabrics and Their Self-Cleaning and Physiological Comfort Properties
}

\author{
Muhammad Zaman Khan ${ }^{1, *}$, Jiri Militky ${ }^{1} \oplus$, Michal Petru ${ }^{2} \oplus$, Blanka Tomková ${ }^{1}$, Azam Ali ${ }^{1}$, Asif Javed ${ }^{1}$, \\ Musaddaq Azeem ${ }^{1}$ and Dana Křemenáková ${ }^{1}$ \\ 1 Department of Material Engineering, Faculty of Textile Engineering, Technical University of Liberec, \\ 46117 Liberec, Czech Republic; jiri.militky@tul.cz (J.M.); blanka.tomkova@tul.cz (B.T.); azam.ali@tul.cz (A.A.); \\ asif.javed@tul.cz (A.J.); musaddaq.azeem@tul.cz (M.A.); dana.kremenakova@tul.cz (D.K.) \\ 2 Department of Machinery Construction, Institute for Nanomaterials, Advanced Technologies and \\ Innovation (CXI), Technical University of Liberec, 46117 Liberec, Czech Republic; michal.petru@tul.cz \\ * Correspondence: muhammad.zaman.khan@tul.cz; Tel.: +420-774357781
}

check for updates

Citation: Khan, M.Z.; Militky, J.; Petru, M.; Tomková, B.; Ali, A.; Javed, A.; Azeem, M.; Křemenáková, D. Ultra-Fast Growth of ZnO Nanorods on Cotton Fabrics and Their Self-Cleaning and Physiological Comfort Properties. Coatings 2021, 11, 1309. https://doi.org/10.3390/ coatings11111309

Academic Editors: Joaquim Carneiro and Alexandru Enesca

Received: 31 August 2021

Accepted: 25 October 2021

Published: 28 October 202

Publisher's Note: MDPI stays neutral with regard to jurisdictional claims in published maps and institutional affiliations.

Copyright: (c) 2021 by the authors. Licensee MDPI, Basel, Switzerland. This article is an open access article distributed under the terms and conditions of the Creative Commons Attribution (CC BY) license (https:/ / creativecommons.org/licenses/by/ $4.0 /)$.

\begin{abstract}
The main aim of the present study was to investigate the effect of microwave irradiation time on the photocatalytic and physiological comfort characteristics of zinc-oxide-nanorod-coated cotton fabrics. An ultra-fast technique was employed to grow the zinc oxide nanorods on cotton fabrics using a microwave-assisted hydrothermal method. The axial (length) and lateral (diameter) growth of the zinc oxide nanorods was observed to increase with microwave irradiation time. The $\mathrm{ZnO}$ nanorods uniformly and entirely covered the cotton fibers. The surface morphology, topography and chemical characteristics of the $\mathrm{ZnO}$ nanorods were investigated by scanning electron microscopy (SEM), EDS analysis, X-ray diffraction (XRD), atomic force microscopy (AFM) and inductively coupled plasma-optical emission spectrometry (ICP-OES). The degradation of orange II dye under UV light irradiation was observed to assess photocatalytic self-cleaning and solution discoloration ability. The ZnO-nanorod-coated cotton fabrics exhibited excellent photocatalytic activity, as the stains of orange II dye disappeared predominantly within $4 \mathrm{~h}$ and the coated fabrics became almost white after $6 \mathrm{~h}$. Analyses of thermal properties, water vapor permeability (WVP), air permeability and stiffness were also performed to investigate the physiological comfort of the ZnO-nanorodcoated fabrics. The thermal conductivity and thermal absorptivity were observed to increase with an increase in the size and density of the $\mathrm{ZnO}$ nanorods. Moreover, non-significant reductions in water vapor permeability and air permeability were observed with application of the $\mathrm{ZnO}$ nanorods. The stiffness of the $\mathrm{ZnO}$-nanorod-coated cotton fabric increased due to the complete coverage of fibers by the uniform growth of the $\mathrm{ZnO}$ nanorods. The $\mathrm{ZnO}$-nanorod-coated cotton fabrics also showed good washing durability and reusability.
\end{abstract}

Keywords: nanorods; microwave; self-cleaning; photocatalytic; physiological comfort

\section{Introduction}

Zinc oxide $(\mathrm{ZnO})$ is an important $\mathrm{n}$-type semiconductor having a wide band gap $(3.37 \mathrm{eV})$, and a large excitation binding energy of $E_{\mathrm{g}}(60 \mathrm{meV})$ that can cause exciton emission under low excitation energy at room temperature. This wide-band-gap semiconductor material has many functional properties, such as self-cleaning, antimicrobial, photocatalytic, UV resistance, antistatic and piezoelectric properties as well as non-toxicity. Zinc oxide nanoparticles are utilized in catalytic reaction processes due to their large surface area and high photocatalytic property. Synthesis of $\mathrm{ZnO}$ nanostructures with controlled morphology is usually carried out using microwave assisted synthesis techniques [1]. $\mathrm{ZnO}$ nanoparticles have many applications, such as for UV blocking and use in textiles, medical applications, sensors, electronics and electrical engineering. $\mathrm{ZnO}$ nanoparticles have excellent photocatalytic properties, show high stability, enhanced crystallinity and reduced defects. ZnO nanoparticles are used effectively in the photocatalytic degradation of various 
microbes and organic impurities. The most recent research indicates that the risks and advantages of $\mathrm{ZnO}$ nanoparticles depend on the synthesis technique and concentration of $\mathrm{ZnO}$ [2]. The in vitro cytotoxicity of $\mathrm{ZnO}$ nanoparticles depends on the solubility of the $\mathrm{ZnO}$. The presence of $\mathrm{Zn}^{2+}$ at low concentrations is important for maintaining cellular processes and metabolism but at higher concentrations $\mathrm{Zn}^{2+}$ can cause toxicity. Textile coating with a low concentration of $\mathrm{ZnO}$ nanoparticles has been shown not to compromise cell viability; the in situ synthesis of $\mathrm{ZnO}$ nanoparticles may reduce cytotoxicity compared to that occurring with deposition of pre-synthesized $\mathrm{ZnO}$ nanoparticles onto a polymeric material [3]. Photocatalytic self-cleaning occurs due to photocatalysis whereby organic molecules are broken down to simpler species, such as carbon dioxide $\left(\mathrm{CO}_{2}\right)$ and water $\left(\mathrm{H}_{2} \mathrm{O}\right)$, on exposure to UV light. The UV radiation activates the photocatalyst deposited on the surface which generates the active species capable of degrading organic chemicals. In the photocatalytic reaction, electromagnetic radiation with a photon energy (given by its wavelength $\lambda(\mathrm{nm})$ ) at least equal to the band gap of the semiconductor $E_{\mathrm{g}}(\mathrm{eV})$ should be used.

Recently, microwave assisted synthesis has gained much attention due to many advantages compared to conventional heating techniques. Microwave-assisted synthesis is a new green chemistry approach and has been shown to reduce energy consumption, time, cost and waste materials hazards. It has also been shown to increase the synthesis rate, reaction rate, bulk production rate, physicochemical properties, purity of materials and temperature homogeneity of the system [4]. In this approach, microwaves are able to penetrate the material and supply energy to the system; heat can be produced throughout the volume of the material resulting in volumetric heating [5].

Microwave-assisted techniques have been used in wet chemical reactions and the synthesis of nanostructures. In conventional heating methods, heat is transferred by convection when the vessel is heated. Microwave-assisted hydrothermal methods are more efficient in comparison to conventional hydrothermal methods due to their reduced energy consumption, rapid synthesis, rapid heating, simple medium and their ability to control morphology synthesis. During microwave heating, electromagnetic energy is converted to thermal energy; the heat caused by the electrical component of an electromagnetic field is mainly due to dipolar polarization and conduction [6]. Microwave synthesis methods have most often been used in the production of $\mathrm{ZnO}$ nanostructures due to their simplicity, and rapid and uniform process [7-10]. Recently, much work has been carried out utilizing different hydrothermal methods in connection with the growth and synthesis of different $\mathrm{ZnO}$ nanostructures, such as nanorods, nanowires, nanoflowers, nanotubes, nano-pillars and nano-spheres. Challenges remain, however, for the design of an energy efficient, ultra-fast, low cost, simple, eco-friendly and inexpensive process for the synthesis of $\mathrm{ZnO}$ nanostructures. Microwave-assisted heating techniques have emerged as a promising means of achieving rapid heat transfer, volumetric increase, enhanced reaction rate and reduced reaction time compared to conventional heating techniques [11,12].

In a previous study, the radio-frequency sputtering method was used to deposit seed layers onto glass substrates and to subsequently synthesize $\mathrm{ZnO}$ nanowires arrays onto these seeded glass substrates using a low-temperature solution technique [13]. Preda et al. fabricated multi-functional cotton fabrics coated with hexagonal $\mathrm{ZnO}$ prisms using an electroless deposition method [14]. Thi et al. developed multi-functional UV protective and self-cleaning cotton fabric using microwave-assisted synthesis of different $\mathrm{ZnO}$ crystal nanostructures under different $\mathrm{pH}$ conditions; coffee stains on the $\mathrm{ZnO}$-nanoparticle- coated cotton fabrics had substantially disappeared after $15 \mathrm{~h}$ under UV light [15]. Ennaceri et al. reported the synthesis of hexagonal nanorods using low-temperature electrochemical deposition of nanorods with a mean length and diameter of $710 \mathrm{~nm}$ and $156 \mathrm{~nm}$, respectively [16]. Previously, hybrid composite $\mathrm{ZnO}-\mathrm{TiO}_{2}$ systems were developed by deposition of titanium dioxide by the sol gel method onto $\mathrm{ZnO}$ nanorods grown on an ITO substrate using a hydrothermal method. The photocatalytic activity of the hybrid system was investigated through decolorization of methylene blue dye in aqueous solution [17]. In another study, a 
conventional hydrothermal technique was utilized to grow $\mathrm{ZnO}$ nanorods on polyester fabrics. The nanorod-coated fabrics exhibited stain degradation and solution discoloration of azo dyes under UV irradiation [18]. Recently, ultrasound and microwave assisted techniques were used to enhance the electrocatalytic performance of cobalt and carbon composite materials [19]. The microwave irradiation methods can produce nanostructures with high quality and controlled size and morphology [20]. In a previous study, the microwave irradiation time and the $\mathrm{pH}$ value of the solution was found to have a significant effect on the surface morphology of $\mathrm{ZnO}$ nanostructures [21]. $\mathrm{ZnO}$ nanorods have been grown onto textiles using a low temperature conventional heating method; the grown nanorods were approximately $10-50 \mathrm{~nm}$ and $300-500 \mathrm{~nm}$ in diameter and length, respectively [22].

The physiological comfort properties of nanoparticle-coated-textiles have recently received much attention due to market demands. Comfort is usually described as the absence of unpleasantness and discomfort. Fabric comfort may be divided into three main categories, including thermo-physiological comfort, sensorial comfort and psychological comfort. The thermal comfort of the fabric is mostly related to the movement of heat, air and moisture through fabric, and to keeping the wearer dry while sustaining a constant body temperature $[23,24]$. The comfort properties of the textiles require not be compromised during coating of the nanostructures onto the textiles.

The influence of nanoparticle size and shape on the photocatalytic and comfort properties of coated fabrics has been demonstrated but, to the best of our knowledge, no work has been reported that has examined the influence of the size and shape of zinc oxide nanorods on the photocatalytic and comfort properties of coated fabrics. An ultra-fast approach was employed in this study to grow zinc oxide nanorods on cotton fabric through an all-solution two-step microwave-assisted hydrothermal method.

In the present study, a microwave-assisted hydrothermal technique was employed on cotton fabrics to fabricate the self-cleaning fabric by ultra-fast growth of $\mathrm{ZnO}$ nanorods. An all-solution two-step microwave-assisted hydrothermal technique was utilized to grow the $\mathrm{ZnO}$ nanorods. Firstly, in situ seeding of the cotton fabric was carried out using a microwave-assisted hydrothermal technique. Secondly, ultra-fast growth of $\mathrm{ZnO}$ nanorods was achieved on the seeded cotton fabrics by use of the microwave-assisted hydrothermal technique. The morphology and topography of the $\mathrm{ZnO}$ nanorods were studied using scanning electron microscopy (SEM) and atomic force microscopy (AFM). The structural properties of the $\mathrm{ZnO}$ nanorods were investigated through EDS analysis, inductively coupled plasma-optical emission spectroscopy (ICP-OES), and X-ray diffraction (XRD). The influence of the size and shape of the zinc oxide nanorods on the self-cleaning (photocatalytic) and comfort properties of the coated fabrics were investigated.

\section{Materials and Processes}

\subsection{Materials}

Zinc acetate dihydrate $\left(\mathrm{Zn}\left(\mathrm{CH}_{3} \mathrm{COO}\right)_{2} \cdot 2 \mathrm{H}_{2} \mathrm{O}\right)$, hexamethylenetetramine $\left(\mathrm{C}_{6} \mathrm{H}_{12} \mathrm{~N}_{4}\right)$, absolute ethanol and orange II dye were purchased from Merck (Sigma Aldrich, St. Louis, $\mathrm{MO}$, USA). Zinc nitrate hexahydrate $\left(\mathrm{ZnN}_{2} \mathrm{O}_{6} \cdot 6 \mathrm{H}_{2} \mathrm{O}\right)$ was purchased from Alfa Aesar (Ward Hill, MA, USA). Plain woven $100 \%$ cotton fabric with a real density of $120 \mathrm{~g} / \mathrm{m}^{2}$ was used as a substrate.

\subsection{Seeding and Growth of Nanorods}

A two-step microwave assisted hydrothermal technique was used for the seeding and growth of the $\mathrm{ZnO}$ nanorods onto cotton fabrics. In the first step, the cotton fabric was dipped into a mixed solution containing $30 \mathrm{mM}$ of zinc acetate dihydrate and $90 \mathrm{mM}$ of sodium hydroxide dissolved in ethanol solution. The mixed solution was transferred to the microwave reactor and heated at $90{ }^{\circ} \mathrm{C}$ for $10 \mathrm{~min}$. Finally, the cotton fabric was taken out from the reactor and dried in the oven at $110^{\circ} \mathrm{C}$ for $10 \mathrm{~min}$. The $\mathrm{ZnO}$ nanorods were grown on seeded cotton fabrics with some modifications according to our recently published work [25]. In the second step, $\mathrm{ZnO}$ nanorods were grown on these seeded cotton fabrics 
through a microwave-assisted hydrothermal technique. Equimolar aqueous solutions $(30 \mathrm{mM})$ of zinc nitrate hexahydrate $\left(\mathrm{ZnN}_{2} \mathrm{O}_{6} \cdot 6 \mathrm{H}_{2} \mathrm{O}\right)$ and hexamethylenetetramine (HMTA) were prepared and the seeded cotton fabric was immersed in this solution. The reaction was carried out using a microwave reactor for specified microwave irradiation times $(4,8$, $12 \mathrm{~min}$ ) at $420 \mathrm{~W}$. Finally, the cotton fabrics were rinsed in deionized water and dried in the oven at $110{ }^{\circ} \mathrm{C}$ for $10 \mathrm{~min}$. Figure 1 shows the schematic growth of $\mathrm{ZnO}$ nanorods onto cotton fabric.

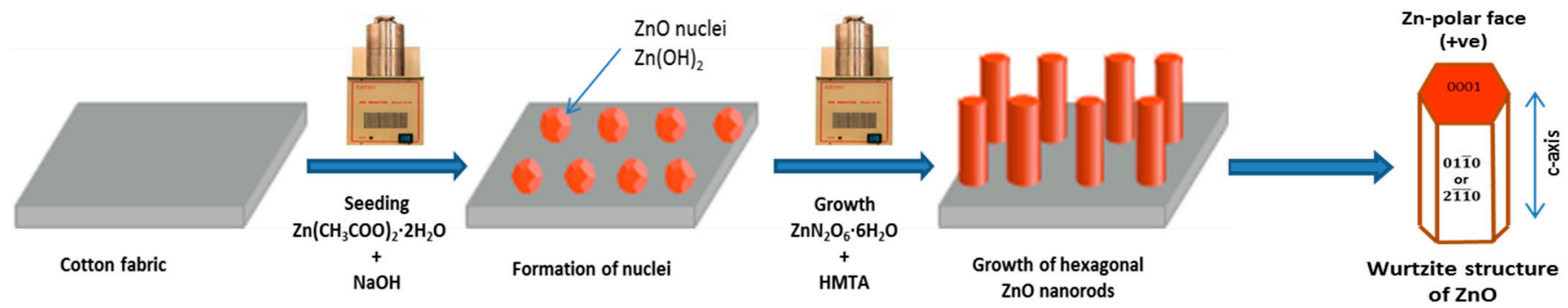

Figure 1. Schematic formation of $\mathrm{ZnO}$-nanorod-coated cotton fabric.

\subsection{Characterization of $\mathrm{ZnO}$ Nanorods}

A Zeiss Ultra Plus scanning electron microscope (SEM) (Zeiss, Oberkochen, Germany) was used to study the surface morphology of coated samples at an accelerating voltage of $2 \mathrm{kV}$. The elemental analysis of the cotton samples was carried out using an Oxford X-max 20 (Oxford, UK) energy dispersive X-ray spectrometer A conductive layer was developed by sputtering of platinum onto the surface of the samples prior to SEM characterization. The X-ray diffraction (XRD) analysis was carried out with an EMPYREAN PAN diffractometer (Malvern Panalytical, Malvern, UK) equipped with a PIXcel3D detector, using Cu $\mathrm{k} \alpha 1$ radiation $(40 \mathrm{kV} ; 30 \mathrm{~mA} ; \lambda=0.1789 \mathrm{~nm})$. The XRD pattern was recorded with a step size of $0.026^{\circ}$ in a $2 \theta$ range from $5^{\circ}-105^{\circ}$. The topography and surface roughness of the coated samples were evaluated in non-contact mode using an AFM (NanoWizard 3 NanoScience) from JPK Instruments (JPK BioAFM-Bruker, Berlin, Germany). The amount of Zn content deposited onto coated samples by microwave irradiation was calculated by inductively coupled plasma-optical emission spectroscopy (ICP-OES) using a Perkin Elmer Optima 2100DV spectrometer (Waltham, MA, USA).

\subsection{Photocatalytic Activity}

The photocatalytic performance of the $\mathrm{ZnO}$-nanorod-grown fabrics was studied by stain degradation and a solution discoloration test. The Orange II dye was used to evaluate the photocatalytic activity. The staining of the $\mathrm{ZnO}$ nanorod-grown-fabric was made by immersing the fabric into $0.01 \%(w / v)$ aqueous solution of the Orange II dye and then drying in an oven at $60^{\circ} \mathrm{C}$ for $3 \mathrm{~min}$. The dyed samples were placed under UV light using Philips TL 6W /05CE UV tubes (315-400 nm) (Eindhoven, the Netherlands). The dyed samples were irradiated under UV light for different time intervals to evaluate the stain degradation properties. Finally, after UV irradiation, the discolored fabrics were scanned at 600 dpi and the scanned images were analyzed by Image J software (version 1.53a) [26,27] to calculate the color intensity. For solution discoloration activity, circular pieces of cotton samples with diameter $(2.8 \mathrm{~cm})$ were placed in a beaker containing orange II dye solution $(15 \mathrm{~mL})$ and exposed to the UV light via Philips TL 6W/05CE UV tubes (315-400 nm) at a distance of $18 \mathrm{~cm}$ below the UV light lamp. The photocatalytic discoloration activity was evaluated by removing an aliquot from the solution after a fixed time interval, and its absorbance in the visible region was measured at $\lambda_{\max }$ of $485 \mathrm{~nm}$ using UV-V spectrophotometer UV-1600PC.

\subsection{Characterization of Physiological Comfort Properties}

All cotton fabric samples were conditioned in relative humidity $(65 \% \pm 2 \%)$ at $20 \pm 2{ }^{\circ} \mathrm{C}$ atmospheres for $24 \mathrm{~h}$ before testing. 


\subsection{Thermal Conductivity}

An Alambeta device (Sensora Instruments, Liberec, Czech Republic) was used to measure the thermal conductivity of the cotton samples [28,29]. This device can measure the thermal conductivity, thermal absorptivity, thermal resistance and thickness of the sample. The working principle of this device depends on the heat flow passing through the examined sample due to the difference in temperature of the hot upper plate and cold bottom plate. The thermal conductivity of the sample was calculated by the following Equation (1).

$$
R=\frac{h}{\lambda}
$$

where; " $R$ " is thermal resistance of the fabric samples $\left(\mathrm{m}^{2} \cdot \mathrm{K} \cdot \mathrm{W}^{-1}\right), h$ is sample thickness $(\mathrm{m})$, and $\lambda$ is thermal conductivity $\left(\mathrm{W} \cdot \mathrm{m}^{-1} \cdot \mathrm{K}^{-1}\right)$.

\subsection{Thermal Absorptivity}

The characterization of the thermal feeling during a short contact of fabric surface with human skin is called thermal absorptivity $(b)$. The thermal absorptivity was calculated using the Equation (2) [30].

$$
b=\sqrt{\lambda \rho c}
$$

where $\rho c\left(\mathrm{~J} / \mathrm{m}^{3}\right)$ is thermal capacity of the fabric sample, and $b$ is the thermal absorptivity of the fabric.

\subsection{Relative Water Vapor Permeability}

The relative water vapor permeability (RWVP) of the samples was tested using the PERMETEST apparatus (Sensora instruments) (Liberec, Czech Republic), fast skin model. This apparatus measures the amount of heat passing through the thermal model of human skin [30,31]. The RWVP (\%) of the fabric samples was evaluated according to ISO 11,092 standard [32]. The RWVP was calculated from the following Equation (3) [33].

$$
\mathrm{RWVP}=\frac{q_{v}}{q_{0}} \times 100
$$

where, $q_{v}$ is the heat flow $\left(\mathrm{W} \cdot \mathrm{m}^{-2}\right)$, which is passing through the measuring head with a fabric sample, and $q_{o}$ is the heat flow which is passing through the measuring head without a fabric sample.

\subsection{Air Permeability}

Air permeability of the fabric samples was measured using the Textest FX 3300 instrument (Schwerzenbach, Switzerland) according to standard (EN ISO 9237:1995 [34]) test methodology. The test pressure was maintained at 200 pascales $(\mathrm{Pa})$ on an area of $20 \mathrm{~cm}^{2}$ $\left(\mathrm{m}^{-2} \cdot \mathrm{s}^{-1}\right)$. The measurement was carried out at a pressure of $200 \mathrm{~Pa}$ and in the range of 3 .

\subsection{Stiffness}

The fabric samples were investigated for their comfort properties based on the measurements of stiffness using a Tuhomer TH-4 instrument (Liberec, Czech Republic). The sample is bent to $60^{\circ}$ and force is calculated by the instrument. The relation is given by the following Equation (4).

$$
M_{o}=F \times K
$$

where, $M_{o}$ is the bending moment/stiffness $(\mathrm{mN} \cdot \mathrm{cm}), F$ is the applied force $(\mathrm{mN})$, and $K$ is the constant $(K=0.52)$. The higher the bending force required to bend the fabric at a particular angle, the higher the bending moment, which corresponds to higher stiffness of the textile $[35,36]$. 


\subsection{Washing Durability (Reusability)}

The washing durability of $\mathrm{ZnO}$-nanorod-grown fabrics for photocatalytic self-cleaning after repeated washing was evaluated according to ISO 105 C06 (B1M) [37]. Consistent with this standard, each washing cycle was completed with $4 \mathrm{~g} / \mathrm{L}$ detergent at $50{ }^{\circ} \mathrm{C}$ for a 45 min time interval, which is equal to five home launderings. After washing, the coated fabrics were then rinsed, and dried in an oven at $80^{\circ} \mathrm{C}$ for $5 \mathrm{~min}$. The coated fabrics were then again analyzed for photocatalytic activity.

\section{Results and Discussion}

The surface morphology and topography of the ZnO-grown cotton fabrics were investigated by SEM and AFM. Figure 2a shows the smooth and pristine surface of the uncoated cotton fabric without the presence of $\mathrm{ZnO}$ nanorods. A highly oriented and uniform array of $\mathrm{ZnO}$ nanorods can be observed on the surface of the synthesized cotton fabrics. The $\mathrm{ZnO}$ nanorods entirely covered the surface of the cotton fiber. Moreover, the size of the nanorods was found to increase with an increase in microwave irradiation time, and a denser coating of nanorods was formed. The effective attachment of the $\mathrm{ZnO}$ nanorods on the surface of cotton fibers was due to the presence of hydroxyl $(\mathrm{OH})$ groups and development of bonds between them. Figure $2 \mathrm{~b}-\mathrm{d}$ show the SEM images of the $\mathrm{ZnO}$ nanorod-grown cotton fabrics for different microwave irradiation times $(4,8,12 \mathrm{~min})$.
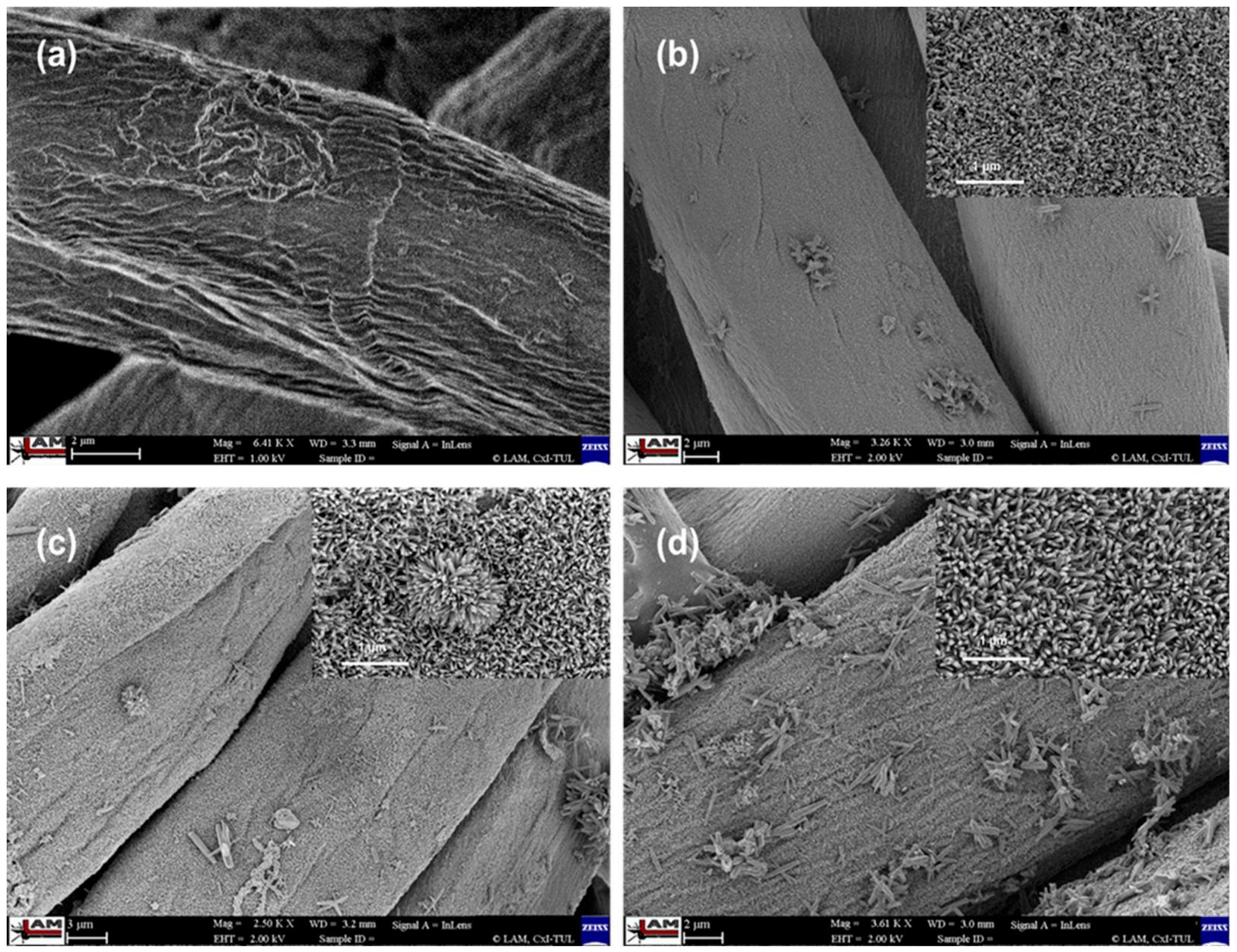

Figure 2. SEM images of the zinc-oxide-nanorod-grown cotton fabric for various microwave irradiation times: (a) 0 min, (b) $4 \mathrm{~min}$, (c) $8 \mathrm{~min}$, and (d) $12 \mathrm{~min}$. The insets are highly magnified corresponding images.

The diameter and length of the grown $\mathrm{ZnO}$ nanorods were $32.9-58.1 \mathrm{~nm}$ and 192.7-289.9 nm, respectively (Table 1 ). The microwave irradiation time was found to 
have a very strong effect on the dimension and shape of synthesized nanorods [38]. The dimensions of the $\mathrm{ZnO}$ nanorods were estimated using Image J software (version 1.53a) and SEM images. A sample of 100 individual nanorods were used to calculate the mean value of the nanorod's diameter and length. The hexagonal structure of the $\mathrm{ZnO}$ nanorods can be seen from the SEM images. The length (L) and diameter (D) were found to increase from 192.7 to $289.9 \mathrm{~nm}$ and 32.9 to $58.1 \mathrm{~nm}$, respectively, when the irradiation time increased from 4 to $12 \mathrm{~min}$. As the hydrolysis and condensation reaction of the chemical bath proceeded to $12 \mathrm{~min}$ (Figure 2d), the amount and size of the $\mathrm{ZnO}$ nanorods were further increased. It was found that the increase of microwave irradiation time affects the length (L) of $\mathrm{ZnO}$ nanorods to a greater extent than their diameter (D) [39].

Table 1. Structural and chemical analysis of $\mathrm{ZnO}$ nanorods.

\begin{tabular}{cccc}
\hline Microwave Irradiation Time (min) & $\begin{array}{c}\text { Mean Diameter (D) of ZnO } \\
\text { Nanorods (nm) }\end{array}$ & $\begin{array}{c}\text { Mean Length (L) of ZnO } \\
\text { Nanorods (nm) }\end{array}$ & Zn Content (ppm) \\
\hline 4 & $32.9 \pm 3.1$ & $192.7 \pm 13.3$ & 15,604 \\
8 & $43.6 \pm 2.1$ & $259.9 \pm 21.8$ & 19,361 \\
12 & $58.1 \pm 5.9$ & $289.9 \pm 19.4$ & 26,829 \\
\hline
\end{tabular}

It can be concluded that the microwave irradiation time is an important factor for tailoring the axial and lateral growth of the $\mathrm{ZnO}$ nanorods $[40,41]$. The ICP-OES analysis confirmed the existence of $\mathrm{ZnO}$ nanorods for all coated cotton fabrics. The $\mathrm{Zn}$ content increased with an increase in microwave irradiation time, as shown in Table 1 . The longer irradiation time causes the further heating of the solution, which increases the further deposition and growth of the $\mathrm{ZnO}$ crystals [9,38]. The amount of $\mathrm{Zn}$ content for microwave irradiation times of 4, 8, and 12 min were estimated as 15,604, 19,361, and 26,829 ppm, respectively.

The composition of the synthesized nanorods was confirmed by energy dispersive X-ray spectroscopy (EDS). The EDS analysis elucidated the purity of the uniformly grown nanorods that were mainly composed of zinc $(\mathrm{Zn})$ and oxygen $(\mathrm{O})$ elements (Figure 3$)$. The uncoated cotton fabric was entirely composed of oxygen $(\mathrm{O})$ and carbon $(\mathrm{C})$ elements. The relative atom ratio of carbon, oxygen, and zinc was estimated to be approximately $57.6 \%$, $34.1 \%$, and $8.3 \%$, respectively. The presence of $\mathrm{Pt}$ was caused by sputtering of platinum onto the samples during SEM analysis.

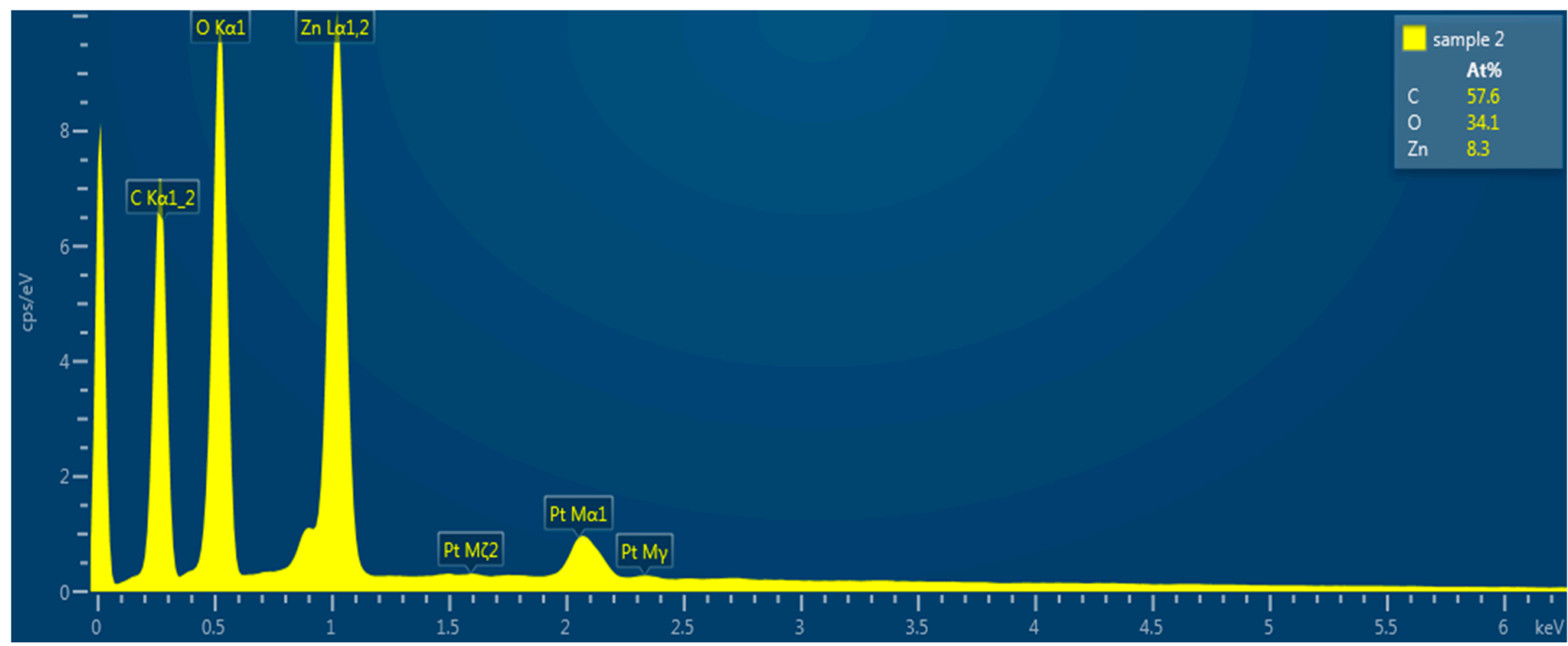

Figure 3. EDS spectrum of zinc-oxide-nanorod-coated cotton fabric. 


\subsection{XRD Analysis}

The cotton fabrics coated with $\mathrm{ZnO}$ nanorods showed typical diffraction peaks of $\mathrm{ZnO}$ and these observed peaks were in good agreement with $2 \theta$ values in the ICCD Card (No. 01-083-6338). The three highest diffraction peaks at 20: $37.1^{\circ}, 40.3^{\circ}$, and $42.4^{\circ}$, which correspond to the (100), (002), and (101) planes of $\mathrm{ZnO}$, confirmed the highly pure and crystalline nature of the nanorods (Figure 4). All of the observed peaks represent the hexagonal wurtzite structure of $\mathrm{ZnO}$ nanorods [8,42,43]. Moreover, no further peaks of impurities were found during the analysis.

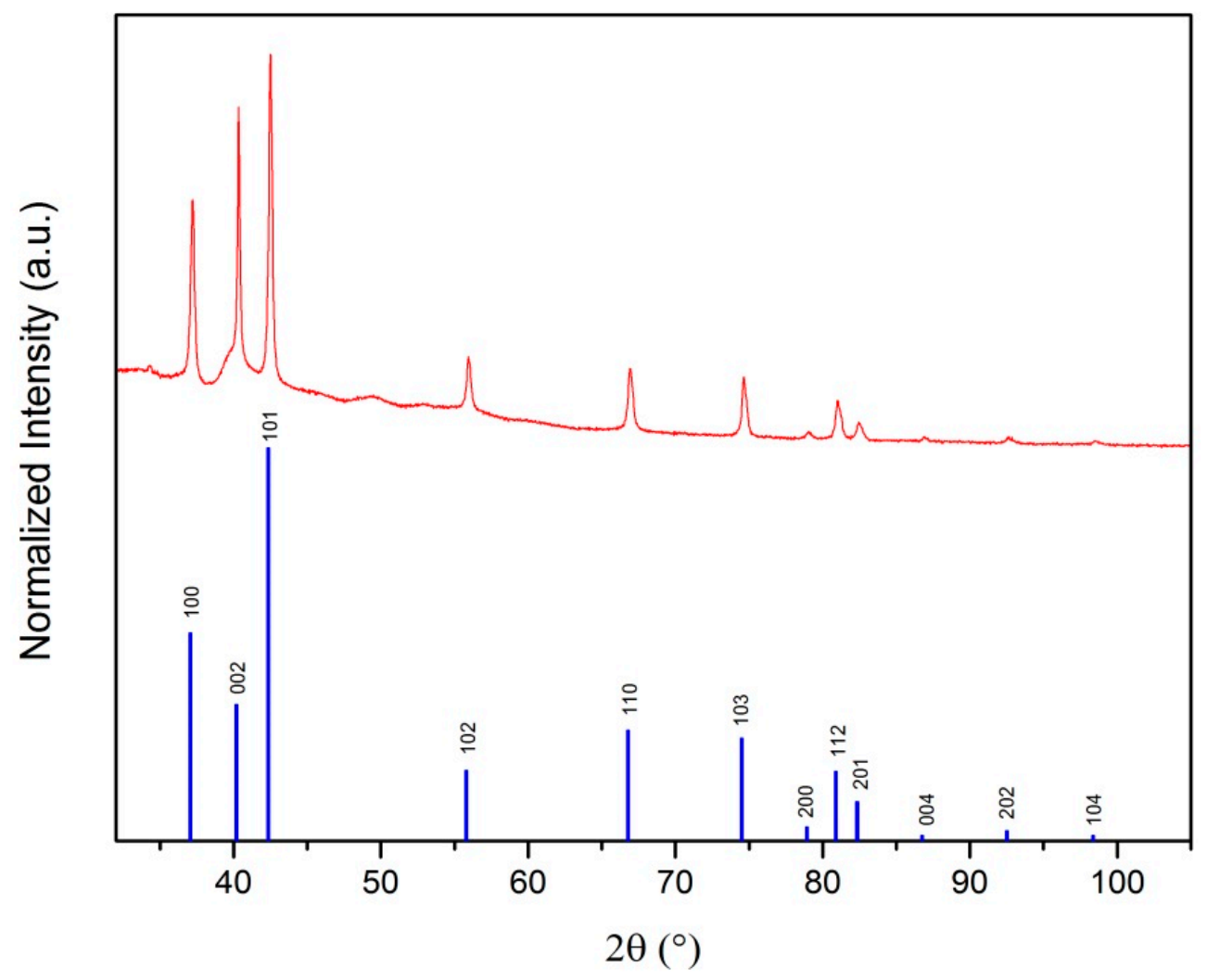

Figure 4. XRD pattern of the zinc-oxide-nanorod-coated cotton fabric.

\subsection{AFM Analysis}

The surface topography of the samples was studied using AFM in non-contact mode. Figure 5 shows topographical 3D and 2D AFM images and surface profiles of the pristine and $\mathrm{ZnO}$-nanorod-coated cotton fabrics. A continuous and homogenous film of the $\mathrm{ZnO}$ nanorods on the cotton fiber surface can be seen from the 3D AFM image (Figure 5b), whereas the pristine cotton fabric had a relatively smooth surface (Figure 5a). A root mean square (RMS) surface roughness value of $89.1 \pm 9.3 \mathrm{~nm}$ was calculated for the $\mathrm{ZnO}$-nanorodcoated cotton fabric. It was observed that after coating with $\mathrm{ZnO}$ nanorods, the surface roughness of the $\mathrm{ZnO}$-nanorod-coated fabric increased many times. 

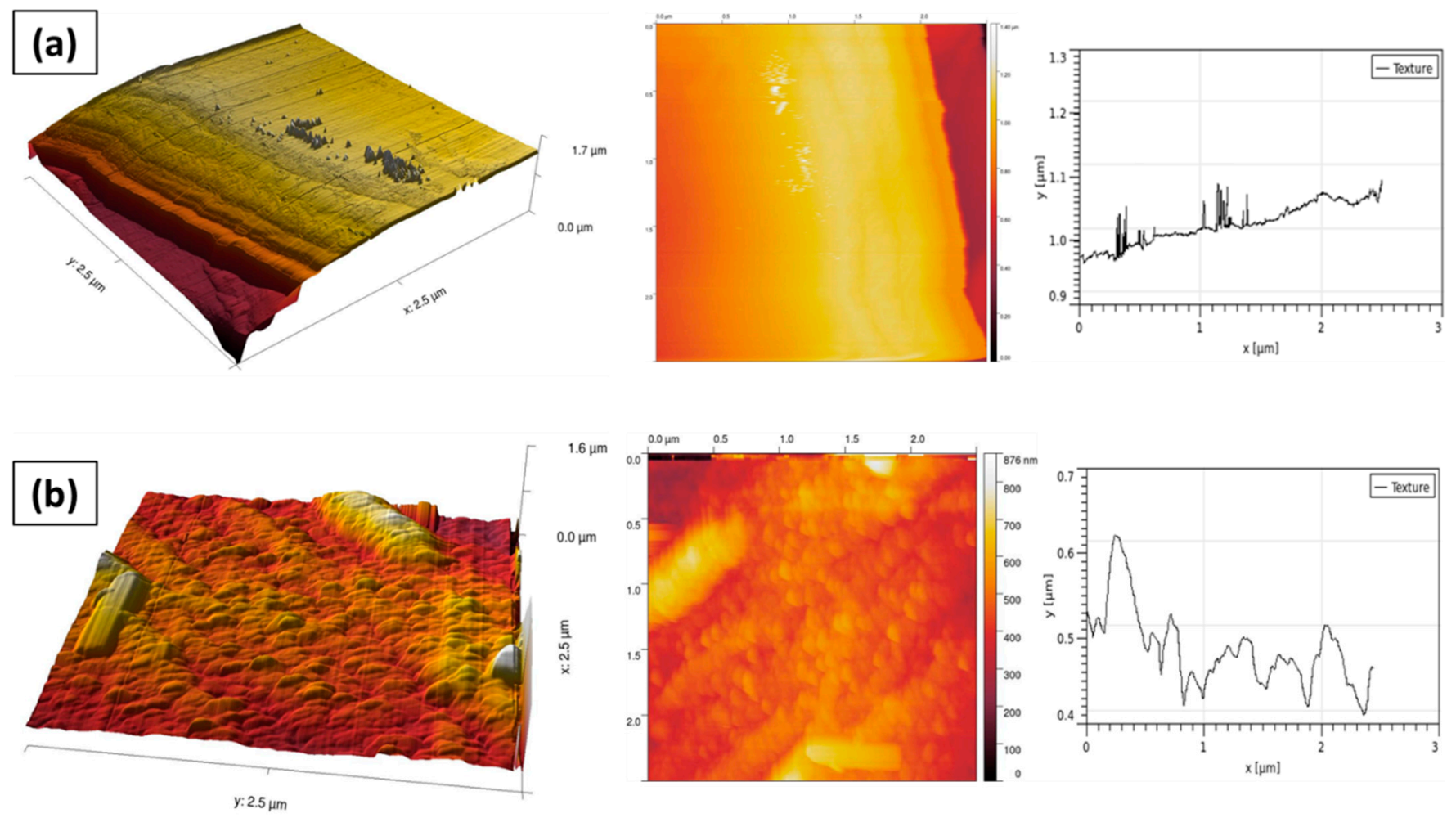

Figure 5. 3D and 2D AFM images and representative surface profiles of (a) pristine cotton fabric, and (b) ZnO-nanorodcoated cotton fabric.

\subsection{Photocatalytic Activity}

The photocatalytic performance of the $\mathrm{ZnO}$-nanorod-coated fabrics was evaluated based on two features: stain degradation and solution discoloration ability. The orange II dye was utilized to evaluate the stain degradation performance. The fabric samples were stained with orange II dye solution and stain degradation activity was studied under ultraviolet (UV) light as a function of time. Figure 6 shows the stain on the pristine and $\mathrm{ZnO}$-nanorod-coated fabric initially and at different time intervals after exposure to UV radiation. Significant stain degradation of the orange II dye was seen on all the $\mathrm{ZnO}$ nanorod-coated fabric samples. Most of the dye stain disappeared within $4 \mathrm{~h}$ and the $\mathrm{ZnO}$-nanorod-coated cotton fabrics became almost white after $6 \mathrm{~h}$. Moreover, the dye degradation rate was observed to increase with an increase in the size of the $\mathrm{ZnO}$ nanorods under UV radiation. Conversely, no change in the stain on the pristine cotton fabric was observed after $6 \mathrm{~h}$ exposure to UV light. 
(a)

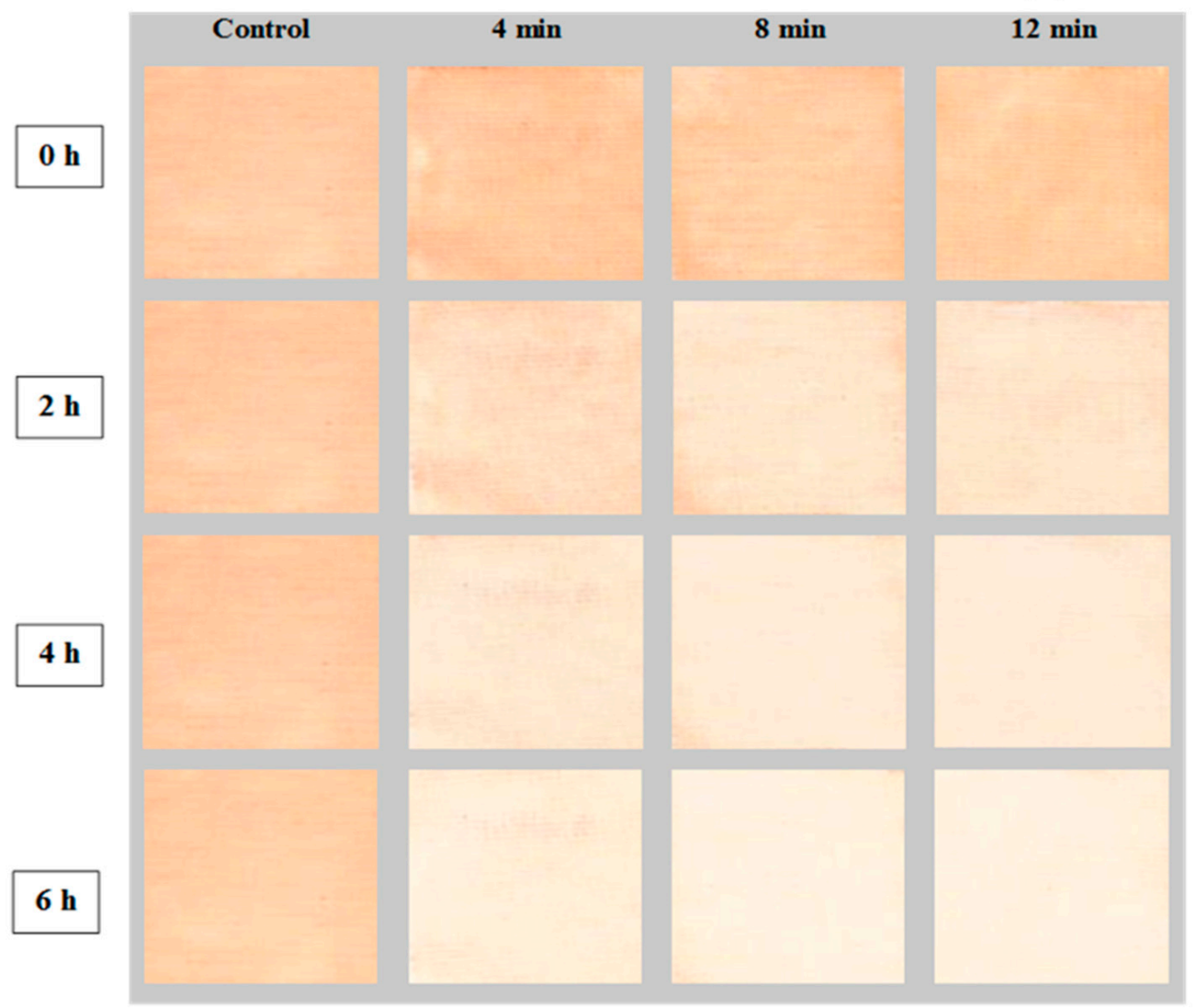

Figure 6. Photocatalytic degradation of the Orange II dye for, (a) control, (b) $4 \mathrm{~min}$, (c) 8 min, and (d) $12 \mathrm{~min}$.

The photocatalytic degradation of the Orange II dye was evaluated by measuring the color intensity of the $\mathrm{ZnO}$-nanorod-coated fabrics by ImageJ software. When the fabric becomes whiter, the color intensity value (counts) increases and indicates the whiteness of the fabric. The measured color intensity from this software is correlated with the whiteness index [26]. The photocatalytic degradation of the dye was found to increase as the color intensity of ZnO-nanorod-coated fabrics increased under exposure to the UV radiation (Figure 7). In contrast, the pristine cotton fabric stained with Orange II dye showed no degradation in the absence of the $\mathrm{ZnO}$ nanorods. The pristine cotton fabric showed a straight line confirming no degradation of Orange II dye in the absence of $\mathrm{ZnO}$ nanorods. The photocatalytic degradation of the $\mathrm{ZnO}$-nanorod-coated fabrics was due to the decomposition of the Orange II dye molecules by generation of highly oxidative radicals under the UV illumination [44]. In this study, the highest photocatalytic activity was shown by the $\mathrm{ZnO}$-nanorod-coated fabric developed under microwave irradiation for $12 \mathrm{~min}$. Initially, the stain degradation rate was rapid, but then slowed. The reason for the high photocatalytic activity under $2 \mathrm{~h}$ was possibly due to the rapid degradation of dye molecules on the top of $\mathrm{ZnO}$ nanorods that were entirely exposed to UV illumination. In contrast, the orange II dye molecules present on the sides of $\mathrm{ZnO}$ nanorods needed greater time to degrade. 


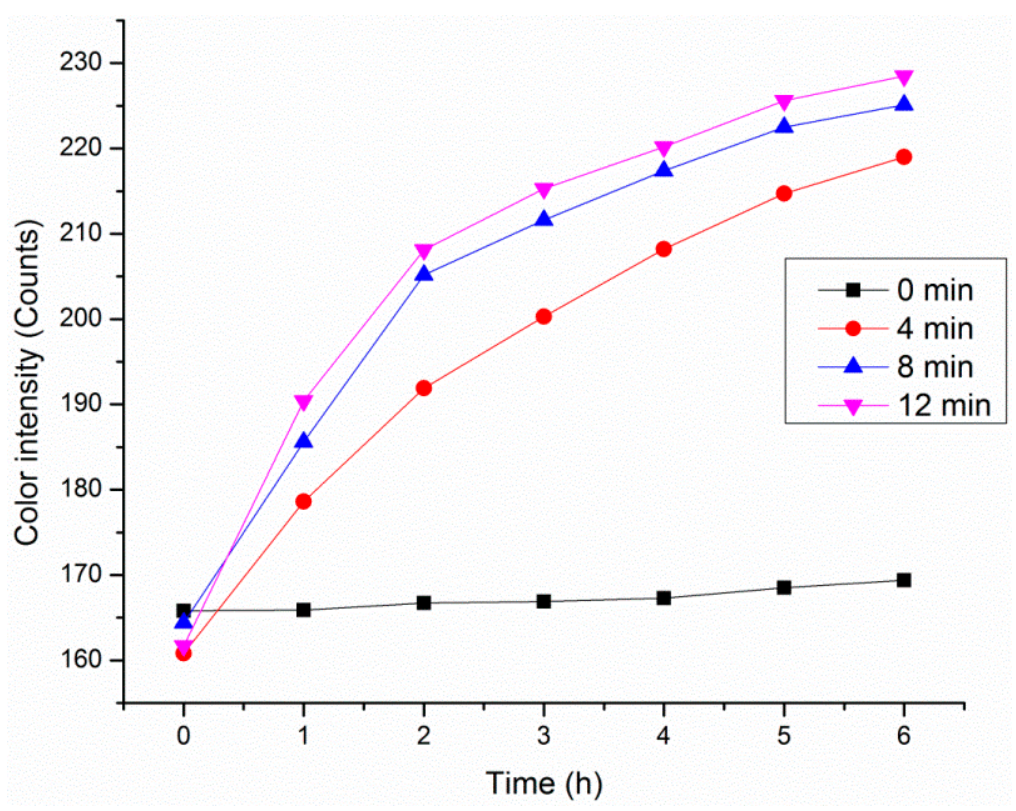

Figure 7. Evaluation of photocatalytic performance of $\mathrm{ZnO}$-nanorod-coated cotton fabrics.

A proposed mechanism for the photocatalytic degradation of Orange II dye by $\mathrm{ZnO}$ nanorods under UV irradiation is shown in Figure 8. When the $\mathrm{ZnO}$ is illuminated by energy higher than its band gap $(3.37 \mathrm{eV})$, the electrons in the valence band jump to the conduction band followed by generation of electron $\left(\mathrm{e}^{-}\right)$and electric hole $\left(\mathrm{h}^{+}\right)$pairs on the surface of the photocatalyst. The negative electrons $\left(\mathrm{e}^{-}\right)$and oxygen $\left(\mathrm{O}_{2}\right)$ combine to form a superoxide radical $\left(\mathrm{O}_{2}{ }^{-}\right)$, while the positive holes $\left(\mathrm{h}^{+}\right)$and water $\left(\mathrm{H}_{2} \mathrm{O}\right)$ produce hydroxyl radicals $(\mathrm{OH})$. Finally, the generated hydroxyl radicals $(\mathrm{OH})$ and the superoxide radical $\left(\mathrm{O}_{2}{ }^{-}\right)$are responsible for the Orange II dye degradation $[45,46]$. A proposed chemical reaction is shown as follows (Equation (5)-(8)):

$$
\begin{gathered}
\mathrm{ZnO}+\mathrm{hv} \rightarrow \mathrm{ZnO}\left(\mathrm{e}^{-}+\mathrm{h}^{+}\right) \\
\mathrm{h}^{+}+\mathrm{H}_{2} \mathrm{O} \rightarrow \mathrm{H}^{+}+\mathrm{OH} \\
\mathrm{O}_{2}+\mathrm{e}^{-} \rightarrow \mathrm{O}_{2}^{-}
\end{gathered}
$$

$$
\mathrm{OH}, \mathrm{O}_{2}^{-}+\text {OrangeIIdye } \rightarrow \text { degradation }
$$

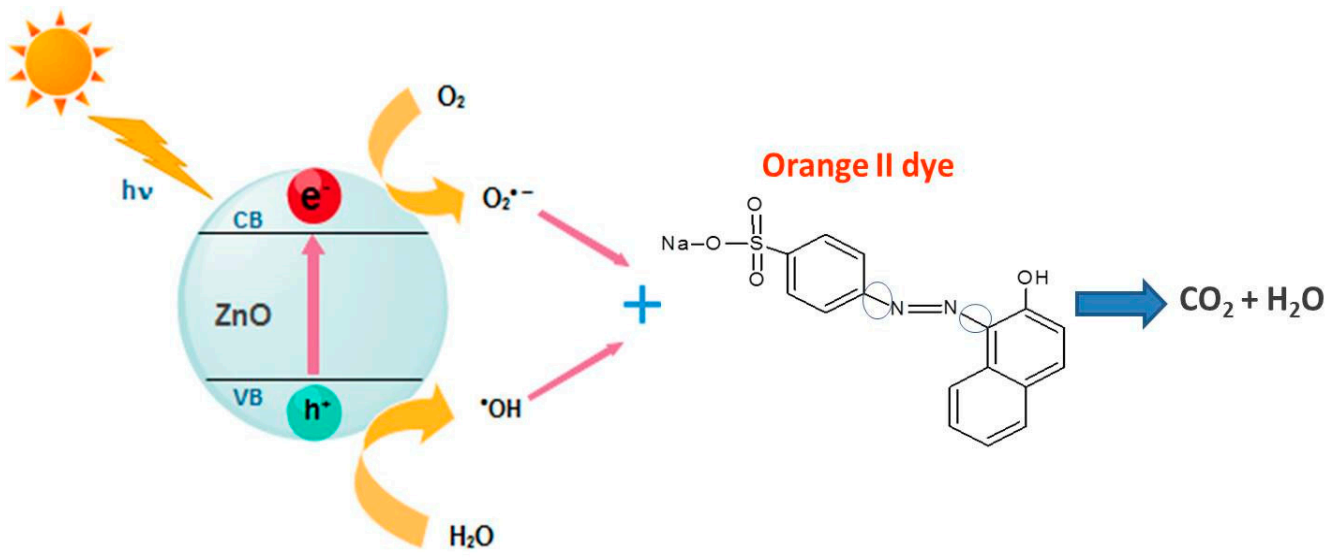

Figure 8. Mechanism of photocatalytic degradation of orange II dye by $\mathrm{ZnO}$ nanorods.

A solution discoloration test was performed to characterize the photocatalytic activity of the $\mathrm{ZnO}$-nanorod-grown cotton fabrics. The nanorod-grown fabrics were immersed in 
the Orange II dye solution and the photocatalytic activity was evaluated as a function of UV irradiation time. The absorbance spectra were used to measure the concentration of the dye solution at different UV irradiation times. The pristine cotton fabric showed no significant change in the absorbance value of the dye solution confirming the absence of photocatalytic activity. Figure 9 represents the absorbance spectra of the Orange II dye solution at different UV irradiation times. The peak intensity at $485 \mathrm{~nm}$ was used to observe the absorbance value of Orange II dye in the solution.

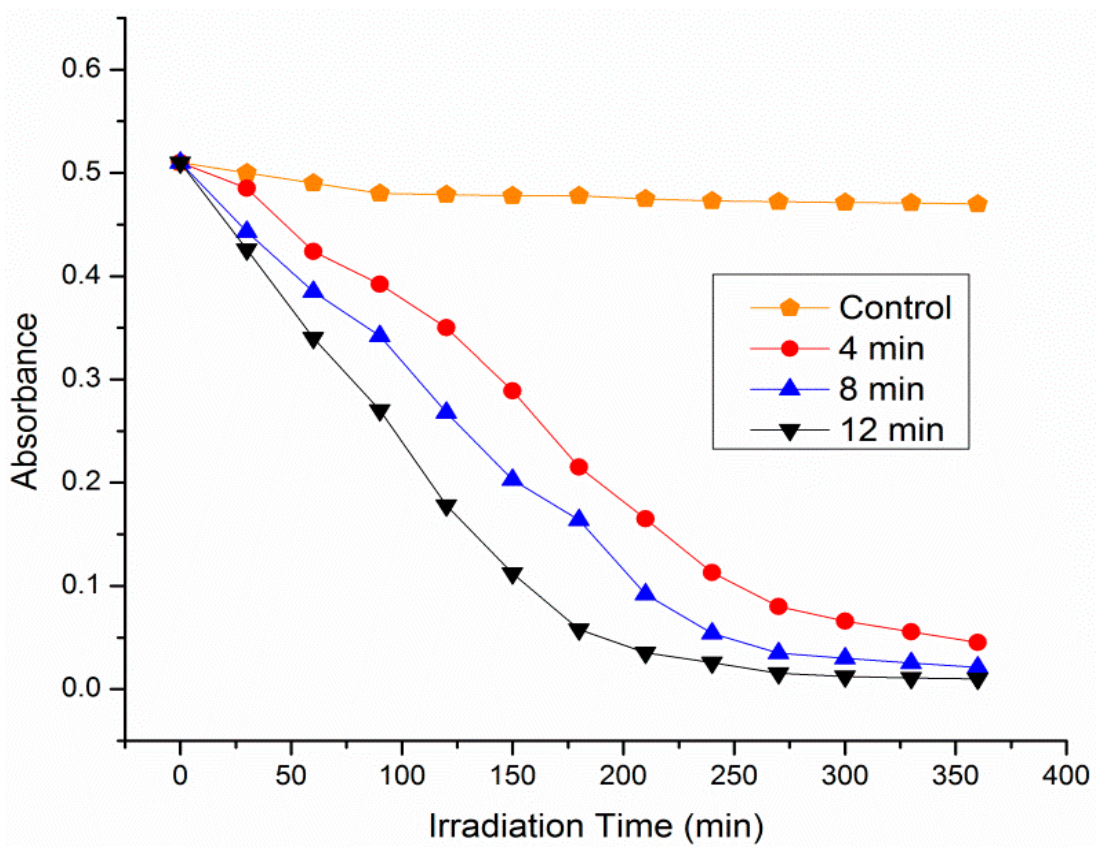

Figure 9. Solution discoloration activity of the $\mathrm{ZnO}$-nanorod-coated fabrics.

The decrease in the absorbance value with the passage of time indicated that the concentration of orange II dye in solution had decreased due to photocatalytic activity. The $\mathrm{ZnO}$ nanorods grown with a microwave irradiation time of $12 \mathrm{~min}$ decolorized the dye solution in $240 \mathrm{~min}$, while the $\mathrm{ZnO}$ nanorods grown with a microwave irradiation time of 4 and $8 \mathrm{~min}$ took $270 \mathrm{~min}$ and $360 \mathrm{~min}$ respectively. The rate of photocatalytic degradation was higher for the $\mathrm{ZnO}$ nanorods grown with $12 \mathrm{~min}$ of microwave irradiation time, which is possibly due to the increase in the size and density of the $\mathrm{ZnO}$ nanorods grown on the fabric surface.

\subsection{Thermal Conductivity}

The thermal conductivity measures the amount of heat which passes from a unit area of the material across a unit thickness under a specific temperature gradient. The thermal properties of the textile, i.e., the thermal conductivity, the thermal absorptivity and the thermal resistance are determined by the fabric structure, fabric density, chemical treatment and properties of the fibers. Figure 10 shows the influence of microwave irradiation time on the thermal conductivity of the $\mathrm{ZnO}$-nanorod-grown fabrics. The thermal conductivity was found to increase with an increase in the microwave irradiation time. A maximum thermal conductivity of $46.2 \mathrm{~W} \cdot \mathrm{m}^{-1} \cdot \mathrm{K}^{-1}$ was achieved for the coated fabric under $12 \mathrm{~min}$ of irradiation time. The thermal conductivity of the $\mathrm{ZnO}$ nanorods was found to be directly proportional to the density and size of the $\mathrm{ZnO}$ nanorods. 


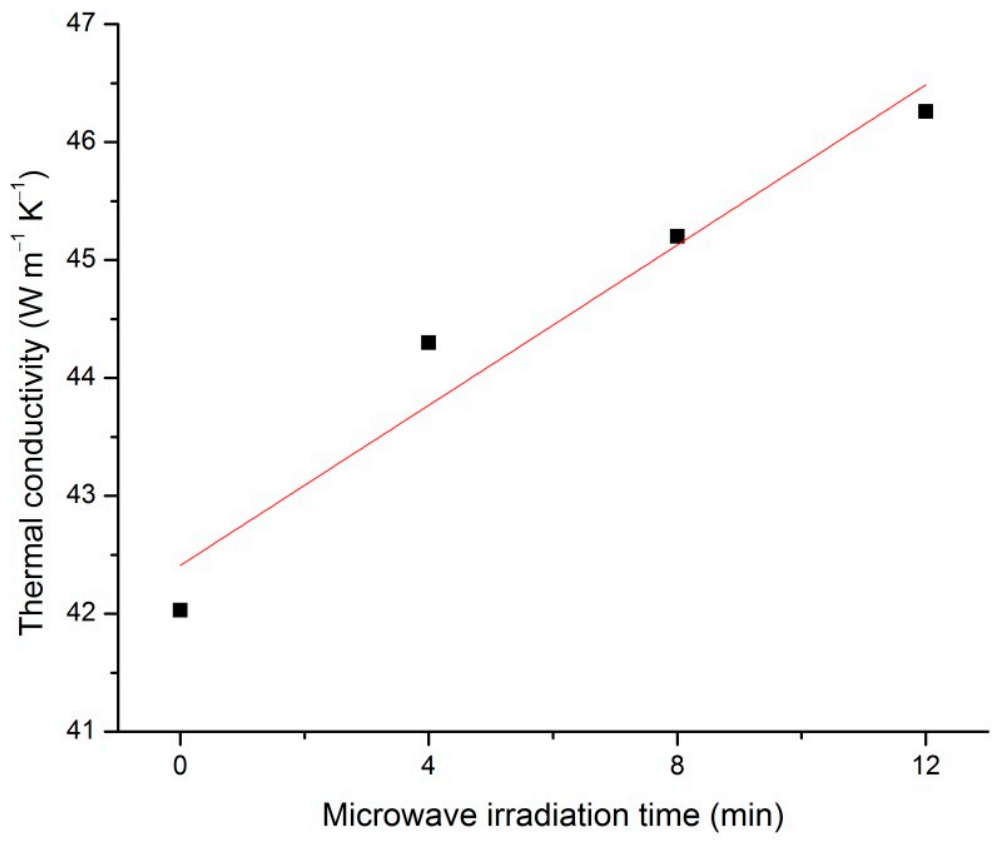

Figure 10. Thermal conductivity of the $\mathrm{ZnO}$-nanorod-coated fabrics for different microwave irradiation times.

It can be concluded that the thermal conductivity increased due to an increase in the diameter and length of the $\mathrm{ZnO}$ nanorods. The thermal conductivity of the smallsized $\mathrm{ZnO}$ nanorods was low compared to those of larger size. In a previous study, the thermal conductivity was found to increase with an increase in the diameter of the $\mathrm{ZnO}$ nanorods [47]. The thermal conductivity was greatly affected by the size and density of the nanorods. The thermal conductivity strongly depends on the diameter of nanorods, exhibiting a decreasing tendency with increase in phonon-surface scattering as the diameter decreases [48]. The size and density of the nanoparticles plays an important role in the thermal conductivity of the materials [49]. The higher thermal conductivity results in the better transfer of heat through fabric. A strong linear trend was observed in the case of thermal conductivity and microwave irradiation time.

\subsection{Thermal Absorptivity}

The thermal absorptivity (b) of fabrics is used to evaluate the thermal feeling during short contact with a body. The greater the thermal absorptivity (b) of the fabric, the cooler it will feel [30]. An increase in the thermal absorptivity of the fabric was observed with higher microwave irradiation time during synthesis of the zinc oxide nanorods (Figure 11). The increase in the thermal absorptivity of the coated cotton fabrics was due to an increase in the size and density of the grown $\mathrm{ZnO}$ nanorods. The thermal absorptivity of the $\mathrm{ZnO}$ nanorods was found to be directly proportional to the size and density of the $\mathrm{ZnO}$ nanorods. The higher thermal absorptivity of the fabric increases the cooling effect and gives comfort to the wearer. A positive linear relationship between the thermal absorptivity and microwave irradiation time was observed. This strong linear behavior can be attributed to the increase in the size of the nanorods with an increase in microwave irradiation time. 


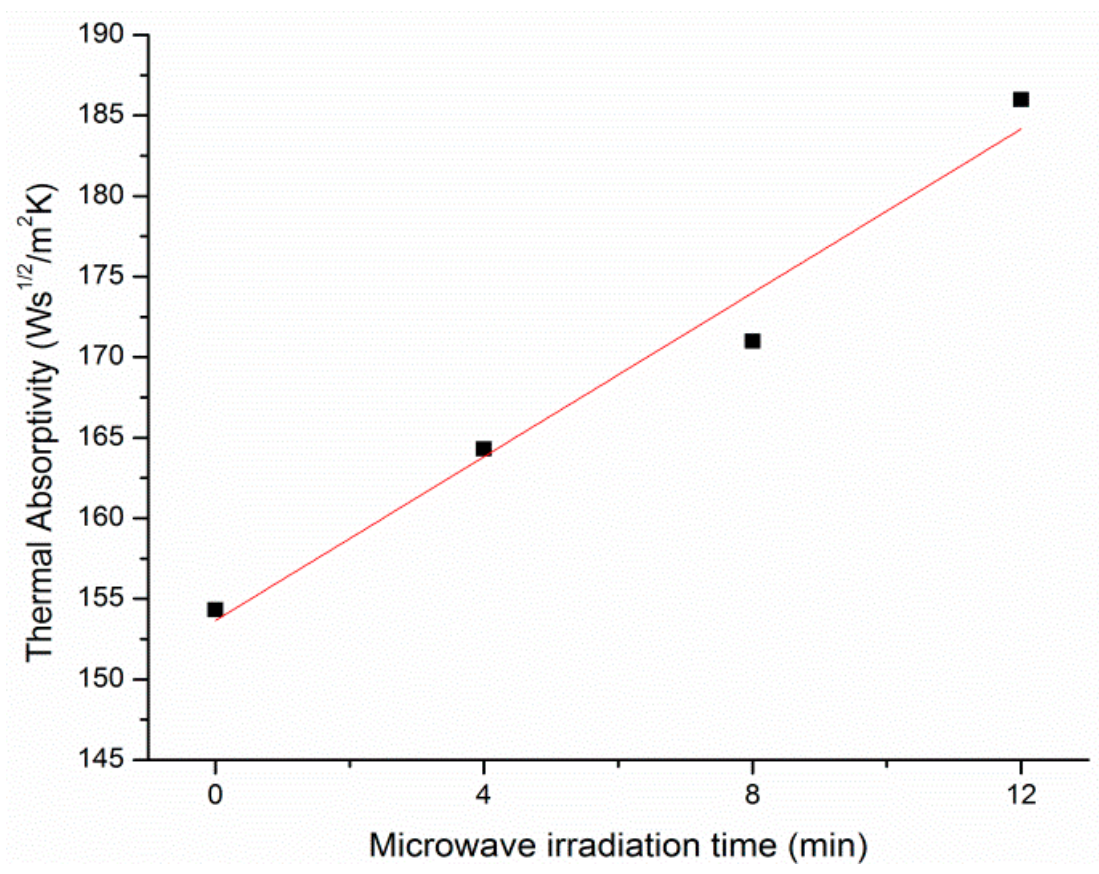

Figure 11. Thermal absorptivity of the $\mathrm{ZnO}$-nanorod-coated fabrics at different microwave irradiation times.

\subsection{Water Vapor Permeability}

The relative water vapor permeability (RWVP) and water vapor resistance (Ret) are important properties for the evaluation of the comfort of textiles. The higher the RWVP, the lower the Ret, and the better the thermal comfort of the textile. The RWVP of the ZnOnanorod-coated fabrics was less affected by different microwave irradiation times. No significant change in RWVP was observed for $\mathrm{ZnO}$-nanorod-grown cotton fabrics. This was due to the presence of uniform and vertically oriented nanorods on the fiber surface so that the porous structure of the fabric was not choked by the growth of the $\mathrm{ZnO}$ nanorods. The RWVP value was $75.8 \%$ for pristine cotton fabric, while RWVP values of $73.5 \%, 72.4 \%$ and $70.6 \%$ were obtained for $\mathrm{ZnO}$-nanorod-coated fabrics under microwave irradiation times of 4,8 , and $12 \mathrm{~min}$, respectively. The relative water vapor permeability was slightly reduced $(5.2 \%)$, which is acceptable, as shown in Figure 12a. In a previous study, for fabric coated with $\mathrm{ZnO}$ the water vapor permeability was reduced by approximately $22 \%-28 \%$ [50]. Similarly, a slight increase in water vapor resistance (Ret) was observed for ZnO-nanorodcoated fabrics, which was possibly due to the entrapment of water vapor in the grooves of the $\mathrm{ZnO}$ nanorod film (Figure 12b). From these results, it can be concluded that no significant change was observed in the water vapor permeability of the $\mathrm{ZnO}$-nanorodcoated fabrics and that they exhibited positive physiological comfort properties. 


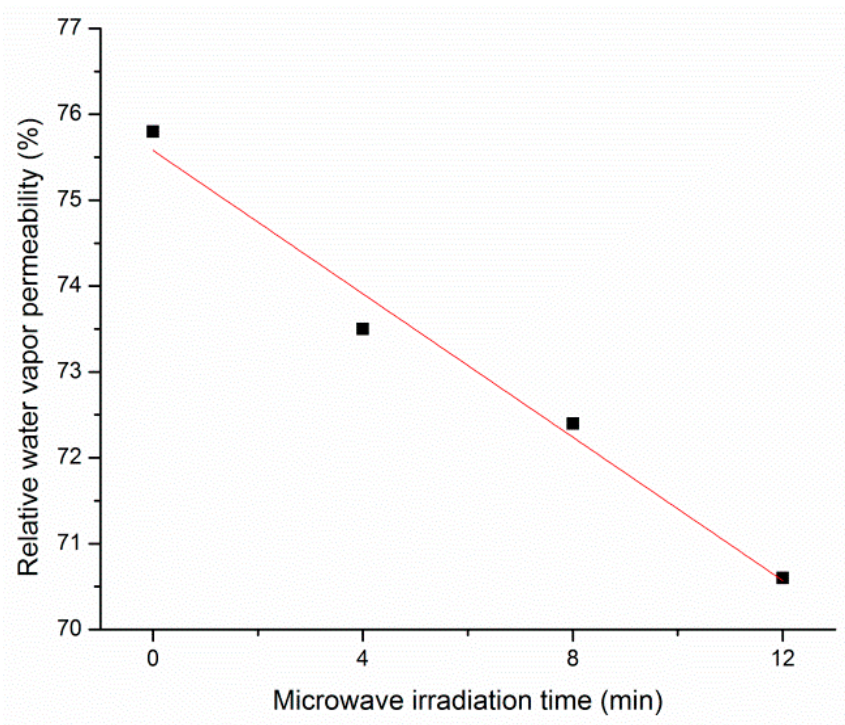

(a)

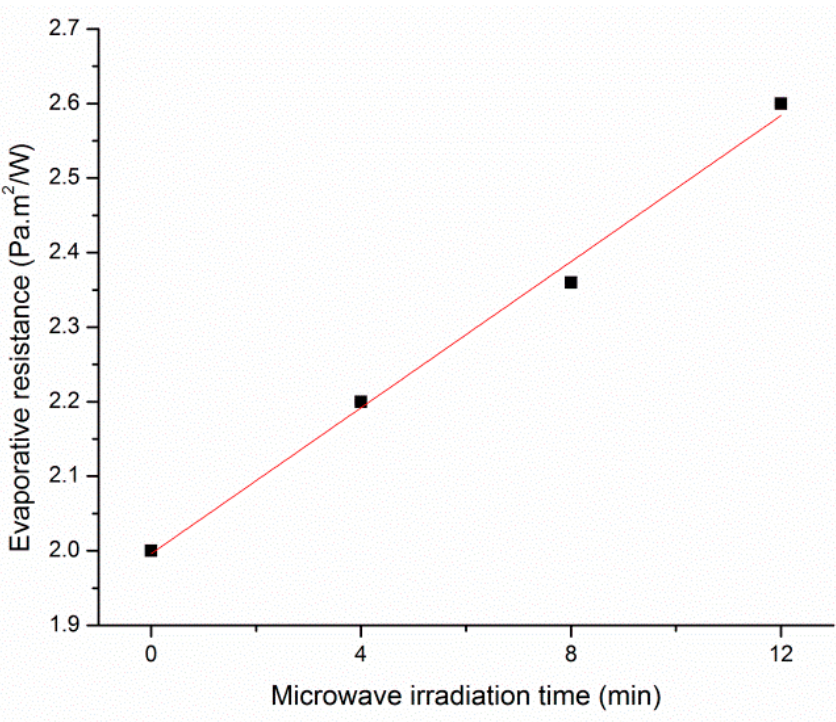

(b)

Figure 12. Water vapor permeability of the ZnO-nanorod-coated fabrics at different microwave irradiation times. (a): Relative water vapor permeability (RWVP), (b): Water vapor resistance (Ret).

\subsection{Air Permeability}

The air permeability relies on the porosity of the fabric, cross-section, shape and number of channels in the fabric. Moreover, the thermal properties of the fabric are mostly affected by air permeability [33]. The air permeability is an important comfort property of textile fabrics. It is also important to investigate the influence of coating on the air permeation of the fabric. The effect of microwave irradiation time on air permeability of the ZnO-nanorod-grown cotton fabrics is shown in Figure 13. A linear trend of reduction in air permeability with increase in irradiation time was observed. Moreover, the air permeability of the nanorod-grown cotton fabric decreased with increase in size and density of the $\mathrm{ZnO}$ nanorods. The air permeability was found to be in the range of 89.3 to $127.3 \mathrm{~lm}^{-2} \cdot \mathrm{s}^{-1}$. Air permeability values of $112,104.6$ and $89.3 \mathrm{~lm}^{-2} \cdot \mathrm{s}^{-1}$ were recorded for ZnO-nanorod-grown fabrics with microwave irradiation times of 4,8 and $12 \mathrm{~min}$, respectively. The drop in air permeability was somewhat less, indicating that the nanorods were covering the fiber surfaces only without blocking the pores of the fabric structure. The air permeability (AP) is attributed to porosity and breathability of textile substrate. A significant decrease in air permeability results in significant reduction in physiological comfort of the fabric [35,51]. However, little significant deterioration of air permeability was observed for the $\mathrm{ZnO}$ nanorod-coated fabrics. The minor reduction in air permeability was possibly due to the decrease in the pore sizes of the fabric caused by the growth of nanorods on the cotton fiber surface. 


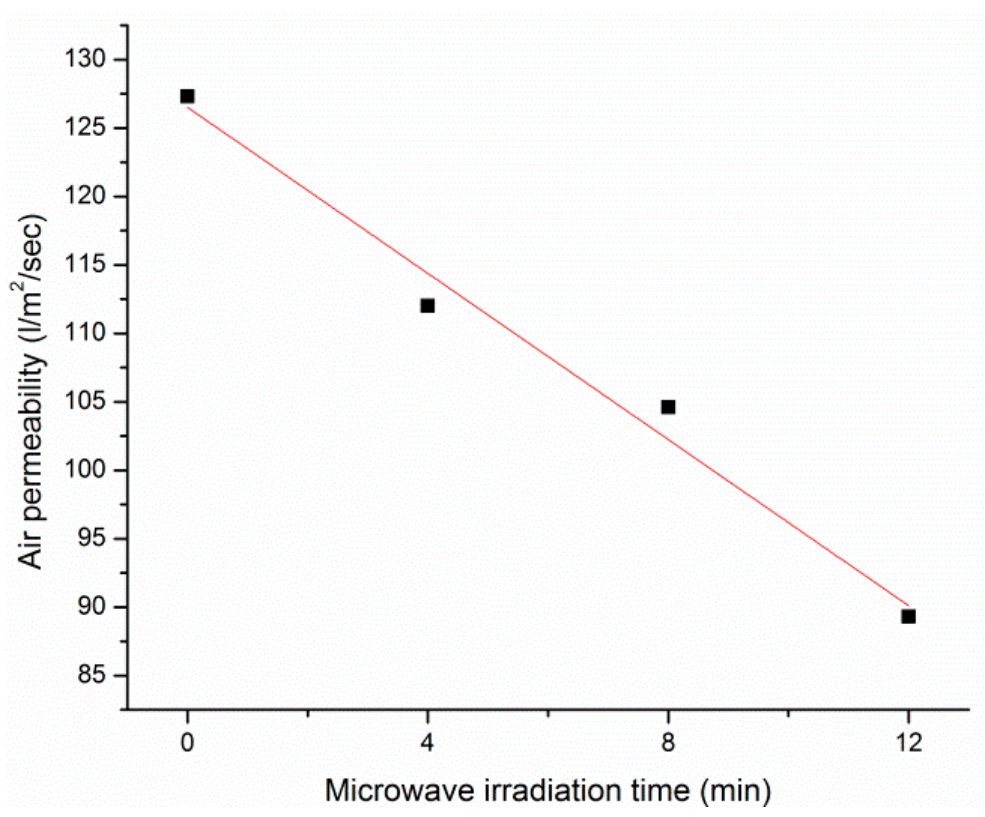

Figure 13. Air permeability property of the ZnO-nanorod-coated fabric at different microwave irradiation times.

\subsection{Stiffness}

The bending force was measured to calculate the stiffness of the fabric samples using a Tuhomer TH-4 instrument (Liberec, Czech Republic). As shown in Figure 14, the stiffness of the $\mathrm{ZnO}$-nanorod-coated fabrics increased with increase in microwave irradiation time. A positive linear relationship was found between the stiffness and the irradiation time. The stiffness was found to increase more as the size and amount of nanorods increased. These findings show that the synthesis of $\mathrm{ZnO}$ nanorods had a moderate effect on the stiffness of the cotton fabrics; thus the sensorial comfort of the ZnO-nanorod-grown cotton fabric was not much affected.

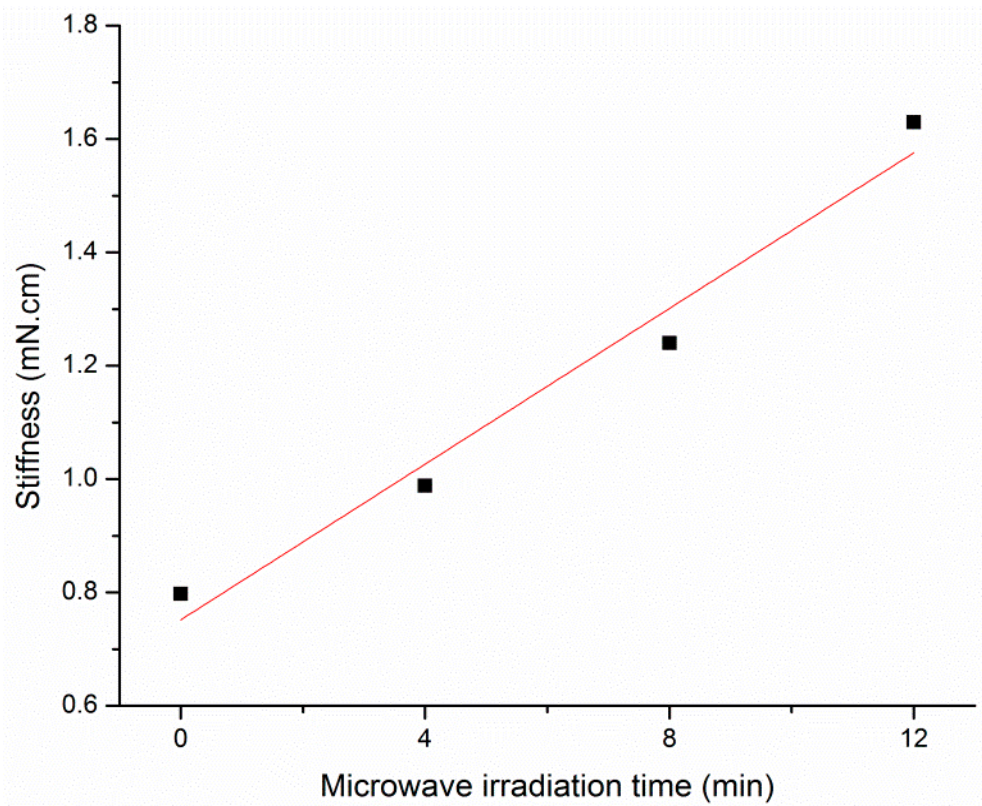

Figure 14. Stiffness of the $\mathrm{ZnO}$-nanorod-coated fabric at different microwave irradiation times. 


\subsection{Washing Durability (Reusability)}

The washing durability of the $\mathrm{ZnO}$-nanorod-grown fabrics was evaluated. The photocatalytic degradation of Orange II dye was evaluated by measuring the color intensity of $\mathrm{ZnO}$-nanorod-coated fabrics after a number of washing cycles. The coated fabrics were subjected to 5, 10, 15 and 20 washing cycles. The photocatalytic activity of the $\mathrm{ZnO}$ nanorod-grown cotton fabrics was not significantly decreased with increased number of washing cycles and they retained very strong photocatalytic activity (Figure 15). The $\mathrm{ZnO}$-nanorod-grown cotton fabric under $12 \mathrm{~min}$ of microwave irradiation time was less affected by the washing cycles and showed high photocatalytic self-cleaning activity, even after 20 washing cycles. These results show that the $\mathrm{ZnO}$ nanorods are strongly attached to the surface of the cotton fibers. Moreover, these findings confirm the durability and reusability of the $\mathrm{ZnO}$-nanorod-grown cotton fabric for functional applications.

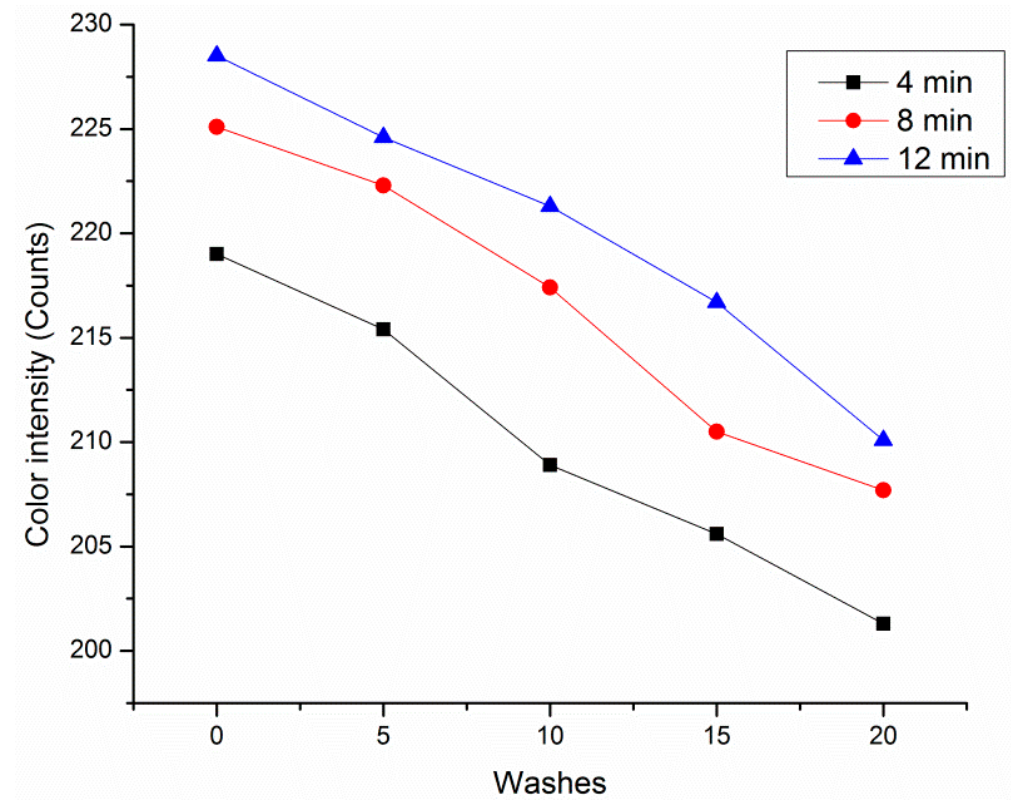

Figure 15. Washing durability and reusability of the $\mathrm{ZnO}$-nanorod-coated fabric at different microwave irradiation times.

\section{Conclusions}

In the present study, an ultra-fast microwave-assisted hydrothermal method was used to grow vertically aligned zinc oxide nanorods on the surface of cotton fabric. The effect of various microwave irradiation times on the self-cleaning and physiological comfort of the $\mathrm{ZnO}$-nanorod-grown fabric was investigated. The axial (length) and lateral (diameter) growth of the $\mathrm{ZnO}$ nanorods was found to have a significant influence on the photocatalytic and physiological comfort properties of the material. Scanning electron microscopy, atomic force microscopy, X-ray diffraction analysis and inductively coupled plasma optical emission spectroscopy were used to investigate the morphological and chemical characteristics of the $\mathrm{ZnO}$ nanorods. The microwave irradiation time greatly affected the growth of the $\mathrm{ZnO}$ nanorods. The size and amount of the nanorods were significantly increased with an increase in microwave irradiation time from 4 to $12 \mathrm{~min}$. The results of XRD analysis indicated the development of a hexagonal wurtzite structure of $\mathrm{ZnO}$ nanorods. The amount of $\mathrm{Zn}$ content on the coated fabric was estimated by ICP-OES analysis. Measurements of stain degradation and solution discoloration were carried out to investigate the photocatalytic and chemical self-cleaning properties. The photocatalytic activity of the nanorod-grown fabric increased with an increase in the length and diameter of the $\mathrm{ZnO}$ nanorods. The dye stain on the $\mathrm{ZnO}$-nanorod-coated cotton fabrics mostly disappeared within $4 \mathrm{~h}$ under UV light. 
The thermal conductivity and thermal absorptivity were found to increase with an increase in the size and density of the $\mathrm{ZnO}$ nanorods. No significant reduction in relative water vapor permeability (RWVP) and air permeability (AP) was observed, possibly due to the uniform covering of the cotton fibers by the growth of vertically aligned $\mathrm{ZnO}$ nanorods without significant depletion of fabric porosity. The stiffness of the $\mathrm{ZnO}$-coated cotton fabric was increased due to the complete and homogeneous coverage of the cotton fibers by the coating of the $\mathrm{ZnO}$ nanorods. The ultra-fast technique employed can be widely applied to grow $\mathrm{ZnO}$ nanorods with excellent photocatalytic self-cleaning and physiological comfort properties.

Author Contributions: Conceptualization, M.Z.K. and J.M.; data curation, A.A. and M.A.; formal analysis, B.T.; funding acquisition, M.P.; investigation, M.Z.K. and A.J.; methodology, M.Z.K.; project administration, M.P.; resources, B.T. and D.K.; software, M.A.; supervision, J.M.; validation, A.A.; visualization, A.J.; writing-original draft, M.Z.K.; writing-review \& editing, J.M. and D.K. All authors have read and agreed to the published version of the manuscript.

Funding: This work was supported by the Ministry of Education, Youth and Sports of the Czech Republic and the European Union European Structural and Investment Funds Operational Program Research, Development and Education project "Modular platform for autonomous chassis of specialized electric vehicles for freight and equipment transportation" (Reg. No. CZ.02.1.01/0.0/0.0/16_025/0007293).

Institutional Review Board Statement: Not applicable.

Informed Consent Statement: Not applicable.

Data Availability Statement: Not applicable.

Acknowledgments: This work was supported by the Ministry of Education, Youth and Sports of the Czech Republic and the European Union European Structural and Investment Funds Operational Program Research, Development and Education project "Modular platform for autonomous chassis of specialized electric vehicles for freight and equipment transportation" (Reg. No. CZ.02.1.01/0.0/0.0/ 16_025/0007293). The authors also acknowledge the support of the project "Textile structures combining virus protection and comfort", Reg. No. CZ.01.1.02/0.0/0.0/20_321/0024467.

Conflicts of Interest: The authors declare no conflict of interest.

\section{References}

1. Hasanpoor, M.; Aliofkhazraei, M.; Delavari, H. Microwave assisted synthesis of zinc oxide nanoparticles. Procedia Mater. Sci. 2015, 8, 320-325. [CrossRef]

2. Czyżowska, A.; Barbasz, A. A review: Zinc oxide nanoparticles-Friends or enemies? Int. J. Environ. Health Res. 2020, 1-17. [CrossRef] [PubMed]

3. Verbič, A.; Gorjanc, M.; Simončič, B. Zinc oxide for functional textile coatings: Recent advances. Coatings 2019, 9, 550. [CrossRef]

4. Ahmad, F.; Idrees, F.; Idrees, F. Recent advancements in microwave-assisted synthesis of NiO nanostructures and their supercapacitor properties: A comprehensive review. Curr. Nanomater. 2018, 3, 5-17. [CrossRef]

5. Mirzaei, A.; Neri, G. Microwave-assisted synthesis of metal oxide nanostructures for gas sensing application: A review. Sens. Actuators B Chem. 2016, 237, 749-775. [CrossRef]

6. Motshekga, S.C.; Pillai, S.K.; Sinha Ray, S.; Jalama, K.; Krause, R.W.M. Recent trends in the microwave-assisted synthesis of metal oxide nanoparticles supported on carbon nanotubes and their applications. J. Nanomater. 2012, 2012, 15. [CrossRef]

7. Kumar, R.; Tiwari, S.; Thakur, V.; Pratap, R. Growth of ultrafast, super dense ZnO nanorods using microwaves for piezoelectric MEMS applications. Mater. Chem. Phys. 2020, 255, 123607. [CrossRef]

8. Kajbafvala, A.; Samberg, J.P.; Ghorbani, H.; Kajbafvala, E.; Sadrnezhaad, S.K. Effects of initial precursor and microwave irradiation on step-by-step synthesis of zinc oxide nano-architectures. Mater. Lett. 2012, 67, 342-345. [CrossRef]

9. Brahma, S.; Rao, K.J.; Shivashankar, S. Rapid growth of nanotubes and nanorods of würtzite ZnO through microwave-irradiation of a metalorganic complex of zinc and a surfactant in solution. Bull. Mater. Sci. 2010, 33, 89-95. [CrossRef]

10. Pimentel, A.; Samouco, A.; Nunes, D.; Araújo, A.; Martins, R.; Fortunato, E. Ultra-fast microwave synthesis of ZnO nanorods on cellulose substrates for UV sensor applications. Materials 2017, 10, 1308. [CrossRef] [PubMed]

11. Kajbafvala, A.; Zanganeh, S.; Kajbafvala, E.; Zargar, H.R.; Bayati, M.R.; Sadrnezhaad, S.K. Microwave-assisted synthesis of narcis-like zinc oxide nanostructures. J. Alloy. Compd. 2010, 497, 325-329. [CrossRef]

12. Fujita, S.; Bhanage, B.M.; Arai, M.; Tambade, P.; Bhatte, K.D. Microwave-assisted additive free synthesis of nanocrystalline zinc oxide. Powder Technol. 2010, 203, 415-418. [CrossRef] 
13. Ji, L.W.; Peng, S.M.; Wu, J.S.; Shih, W.S.; Wu, C.Z.; Tang, I.T. Effect of seed layer on the growth of well-aligned ZnO nanowires. J. Phys. Chem. Solids 2009, 70, 1359-1362. [CrossRef]

14. Preda, N.; Enculescu, M.; Zgura, I.; Socol, M.; Matei, E.; Vasilache, V.; Enculescu, I. Superhydrophobic properties of cotton fabrics functionalized with $\mathrm{ZnO}$ by electroless deposition. Mater. Chem. Phys. 2013, 138, 253-261. [CrossRef]

15. Tran Thi, V.H.; Lee, B.K. Development of multifunctional self-cleaning and UV blocking cotton fabric with modification of photoactive $\mathrm{ZnO}$ coating via microwave method. J. Photochem. Photobiol. A Chem. 2017, 338, 13-22. [CrossRef]

16. Ennaceri, H.; Wang, L.; Erfurt, D.; Riedel, W.; Mangalgiri, G.; Khaldoun, A.; El Kenz, A.; Benyoussef, A.; Ennaoui, A. Waterresistant surfaces using zinc oxide structured nanorod arrays with switchable wetting property. Surf. Coat. Technol. 2016, 299, 169-176. [CrossRef]

17. Kwiatkowski, M.; Bezverkhyy, I.; Skompska, M. ZnO Nanorods covered with a $\mathrm{TiO}_{2}$ layer: Simple sol-gel preparation, and optical, photocatalytic and photoelectrochemical properties. J. Mater. Chem. A 2015, 3, 12748-12760. [CrossRef]

18. Ashraf, M.; Champagne, P.; Perwuelz, A.; Campagne, C.; Leriche, A. Photocatalytic solution discoloration and self-cleaning by polyester fabric functionalized with $\mathrm{ZnO}$ nanorods. J. Ind. Text. 2015, 44, 884-898. [CrossRef]

19. Zuliani, A.; Cano, M.; Calsolaro, F.; Puente Santiago, A.R.; Giner-Casares, J.J.; Rodríguez-Castellón, E.; Berlier, G.; Cravotto, G.; Martina, K.; Luque, R. Improving the electrocatalytic performance of sustainable Co/carbon materials for the oxygen evolution reaction by ultrasound and microwave assisted synthesis. Sustain. Energy Fuels 2021, 5, 720-731. [CrossRef]

20. Chin, C.D.W.; Treadwell, L.J.; Wiley, J.B. Microwave synthetic routes for shape-controlled catalyst nanoparticles and nanocomposites. Molecules 2021, 26, 3647. [CrossRef]

21. Caglar, Y.; Gorgun, K.; Aksoy, S. Effect of deposition parameters on the structural properties of ZnO nanopowders prepared by microwave-assisted hydrothermal synthesis. Spectrochim. Acta.—Part A Mol. Biomol. Spectrosc. 2015, 138, 617-622. [CrossRef] [PubMed]

22. Wang, R.; Xin, J.H.; Tao, X.M.; Daoud, W.A. ZnO nanorods grown on cotton fabrics at low temperature. Chem. Phys. Lett. 2004, 398, 250-255. [CrossRef]

23. Özen, İ.; Çinçik, E.; Şimşek, S. Thermal comfort properties of simulated multilayered diaper structures in dry and wet conditions. J. Ind. Text. 2016, 46, 256-278. [CrossRef]

24. Khan, M.Z.; Hussain, S.; Siddique, H.F.; Baheti, V.; Militky, J.; Azeem, M.; Ali, A. Improvement of liquid moisture management in plaited knitted fabrics. Tekst. Konfeksiyon 2018, 28, 182-188.

25. Khan, M.Z.; Militky, J.; Baheti, V.; Fijalkowski, M.; Wiener, J.; Voleský, L.; Adach, K. Growth of ZnO nanorods on cotton fabrics via microwave hydrothermal method: Effect of size and shape of nanorods on superhydrophobic and UV-blocking properties. Cellulose 2020, 27, 10519-10539. [CrossRef]

26. Khan, M.Z.; Baheti, V.; Militky, J.; Wiener, J.; Ali, A. Self-cleaning properties of polyester fabrics coated with flower-like TiO 2 particles and trimethoxy (octadecyl)silane. J. Ind. Text. 2020, 50, 543-565. [CrossRef]

27. Tang, X.N.; Berman, A.E.; Swanson, R.A.; Yenaris, M.A. Digitally quantifying cerebral hemorrhage using Photoshop ${ }^{\circledR}$ and Image J. J. Neurosci. Methods 2010, 190, 240-243. [CrossRef]

28. Hes, L. Non-destructive determination of comfort parameters during marketing of functional garments and clothing. Indian J. Fibre Text. Res. 2008, 33, 239-245.

29. Mangat, M.M.; Hes, L.; Bajzík, V. Thermal resistance models of selected fabrics in wet state and their experimental verification. Text. Res. J. 2015, 85, 200-210. [CrossRef]

30. Hes, L.; Loghin, C. Heat, moisture and air transfer properties of selected woven fabrics in wet state. J. Fiber Bioeng. Inform. 2009, 2, 141-149.

31. Bogusławska-Baczek, M.; Hes, L. Effective water vapour permeability of wet wool fabric and blended fabrics. Fibres Text. East. Eur. 2013, 97, 67-71.

32. ISO 11092:2014: Textiles_Physiological Effects-Measurement of Thermal and Water-Vapour Resistance under Steady-State Conditions (Sweating Guarded-Hotplate Test); International Organization for Standardization: Geneva, Switzerland, 2014.

33. Hes, L.; de Araujo, M. Simulation of the effect of air gaps between the skin and a wet fabric on resulting cooling flow. Text. Res. J. 2010, 80, 1488-1497. [CrossRef]

34. ISO 9237:1995: Textiles-Determination of the Permeability of Fabrics to Air; International Organization for Standardization: Geneva, Switzerland, 1995.

35. Naeem, J.; Mazari, A.; Volesky, L.; Mazari, F. Effect of nano silver coating on thermal protective performance of firefighter protective clothing. J. Text. Inst. 2019, 110, 847-858. [CrossRef]

36. Fridrichová, L. A new method of measuring the bending rigidity of fabrics and its application to the determination of the their anisotropy. Text. Res. J. 2013, 83, 883-892. [CrossRef]

37. ISO 105-C06:2010: Textiles_-Tests for Colour Fastness_Part C06: Colour Fastness to Domestic and Commercial Laundering; International Organization for Standardization: Geneva, Switzerland, 2010.

38. Ul Hassan Sarwar Rana, A.; Kang, M.; Kim, H.S. Microwave-assisted facile and ultrafast growth of ZnO nanostructures and proposition of alternative microwave-assisted methods to address growth stoppage. Sci. Rep. 2016, 6, 24870. [CrossRef] [PubMed]

39. Shojaee, N.; Ebadzadeh, T.; Aghaei, A. Effect of concentration and heating conditions on microwave-assisted hydrothermal synthesis of ZnO nanorods. Mater. Charact. 2010, 61, 1418-1423. [CrossRef] 
40. Wahab, R.; Kim, Y.S.; Lee, K.; Shin, H.S. Fabrication and growth mechanism of hexagonal zinc oxide nanorods via solution process. J. Mater. Sci. 2010, 45, 2967-2973. [CrossRef]

41. Polsongkram, D.; Chamninok, P.; Pukird, S.; Chow, L.; Lupan, O.; Chai, G.; Khallaf, H.; Park, S.; Schulte, A. Effect of synthesis conditions on the growth of $\mathrm{ZnO}$ nanorods via hydrothermal method. Phys. B Condens. Matter 2008, 403, 3713-3717. [CrossRef]

42. Ates, E.S.; Unalan, H.E. Zinc oxide nanowire enhanced multifunctional coatings for cotton fabrics. Thin Solid Films 2012, 520, 4658-4661. [CrossRef]

43. Cheng, D.; He, M.; Li, W.; Wu, J.; Ran, J.; Cai, G.; Wang, X. Hydrothermal growing of cluster-like ZnO nanoparticles without crystal seeding on PET films via dopamine anchor. Appl. Surf. Sci. 2019, 467-468, 534-542. [CrossRef]

44. Achouri, F.; Merlin, C.; Corbel, S.; Alem, H.; Mathieu, L.; Balan, L.; Medjahdi, G.; Ben Said, M.; Ghrabi, A.; Schneider, R. ZnO nanorods with high photocatalytic and antibacterial activity under solar light irradiation. Materials 2018, 11, 2158. [CrossRef]

45. Chen, X.; Wu, Z.; Liu, D.; Gao, Z. Preparation of ZnO photocatalyst for the efficient and rapid photocatalytic degradation of azo dyes. Nanoscale Res. Lett. 2017, 12, 4-13. [CrossRef]

46. Kajbafvala, A.; Ghorbani, H.; Paravar, A.; Samberg, J.P.; Kajbafvala, E.; Sadrnezhaad, S.K. Effects of morphology on photocatalytic performance of zinc oxide nanostructures synthesized by rapid microwave irradiation methods. Superlattices Microstruct. 2012, 51, 512-522. [CrossRef]

47. Yuldashev, S.U.; Yalishev, V.S.; Cho, H.D.; Kang, T.W. Thermal conductivity of ZnO single nanowire. J. Nanosci. Nanotechnol. 2016, 16, 1592-1595. [CrossRef] [PubMed]

48. Zhang, Z.; Chen, J. Thermal conductivity of nanowires. Chin. Phys. B 2018, 27, 035101. [CrossRef]

49. Mamand, S.M. Thermal conductivity calculations for nanoparticles embedded in a base fluid. Appl. Sci. 2021, 11, 1459. [CrossRef]

50. Dal, V.; Şimşek, R.; Hes, L.; Akçagün, E.; Yilmaz, A. Investigation of thermal comfort properties of zinc oxide coated woven cotton fabric. J. Text. Inst. 2016, 108, 337-340. [CrossRef]

51. Zhu, G.; Kremenakova, D.; Wang, Y.; Militky, J.; Mishra, R. Study on air permeability and thermal resistance of textiles under heat convection. Text. Res. J. 2015, 85, 1681-1690. [CrossRef] 